\title{
Library-Subsidized Unmediated Document Delivery
}

\section{Michaelyn Haslam and Eva Stowers}

Throughout the 1990s, libraries experimented with subsidizing end-user unmediated document delivery as a means of expanding collections, offering faster service, and lessening demands on interlibrary loan. An ongoing project at the University of Nevada, Las Vegas, is presented here to evaluate whether or not providing the service met expectations. For the most part, unmediated document delivery served to enhance collections and users appreciated the service. Since those who preferred to order articles themselves were not necessarily interlibrary loan users, workloads and costs associated with interlibrary loan were not diminished.

Throughout the 1990s, libraries experimented with allowing their users to 1 order articles directly from commercial document suppliers and subsidizing the resulting costs. Permitting the user autonomy in obtaining articles can potentially affect three major areas of library operations: collections, services, and staffing. To a large extent, timely access to nonsubscribed journals expands the collection and does so faster than interlibrary loan. In an era of highly inflationary serials, another benefit of unmediated document delivery is that it can soften the blow of journal cancellations by streamlining the process for obtaining articles. The need for specialized information can be met rapidly and economically through document delivery rather than subscribing to journals desired by a limited population. From a service aspect, unmediated document delivery provides for speedier access to information than traditional interlibrary loan because it eliminates the "middleman" and thus decreases processing and delivery time. Ordering articles for themselves offers a convenience to those users who prefer to take charge of their own document delivery needs or are under severe time constraints. Unmediated document delivery appears to offer a means to reduce interlibrary loan operational expenses, salaries, and staff workloads by transferring the ordering and receiving processes to the requestor.

The constant changes in services and delivery methods that are provided by document suppliers call for a re-evaluation of methods and effectiveness of unmediated document delivery. In this article, we identify reasons for trying unmediated document delivery, evaluate its success or failure in meeting expectations, and present considerations for deciding when using unmediated document delivery is advantageous.

Michaelyn Haslam (mhaslam@ccmail. nevada.edu) is Science Coordinator, Collection Development, and Eva Stowers (estowers@ccmail.nevada.edu) is Science/Reference Librarian at the Lied Library, University of Nevada, Las Vegas.

Manuscript received September 26, 2000; accepted for publication December 19, 2000.

\section{Procedures}

We will describe a recent unmediated document delivery project at the University of Nevada, Las Vegas (UNLV), from the planning of a pilot project to the implementation of a new service. Information gathered regarding usage and 
patron satisfaction will be presented. We will examine the reasons given for trying the service, selection of those who would be allowed to use the service, choice of document supplier(s), training of users, and results of use. The reasons for use can be compared to the results to see whether or not the service worked as expected. Selection of users will be examined to determine whether or not those who used unmediated document delivery were appropriate for achieving the desired outcomes. The quality of service was a function of the choice of document supplier impacting willingness and success in using the service. Training gave users the opportunity to learn to employ the service according to parameters set by the library. Effectiveness of training may determine whether or not the service is cost effective. By examining these elements it is expected that the success of the service in meeting stated needs can be assessed and considerations for implementing unmediated document delivery service can be developed.

\section{Unmediated Document Delivery Projects}

UNLV recently attained Doctoral/Research UniversitiesIntensive status under the 2000 edition of the Carnegie Classification and is actively seeking Doctoral/Research Universities-Extensive status. The university offers degrees in 148 subjects, mostly at the undergraduate and master's degree level and more programs are being developed. Additionally, UNLV conferred 97 doctoral degrees in 14 disciplines over the last five years. The university's goal of building a research-extensive institution means that the faculty of approximately 750 members is expected to achieve high levels of research, scholarship, and publication. Enrollment has been growing at an average rate of $10 \%$ per year over the last ten years and is currently at 15,879 full-time equivalent (FTE). This rather unusual growth rate is due in large part to the rapid growth of metropolitan Las Vegas, where the population increased $63 \%$ in the last decade, from 830,000 in 1990 to an estimated 1.3 million in 1999.

UNLV was founded in 1957, and its relatively brief history has been a barrier to building a substantial research col- lection. Rapid inflation in serials costs, coupled with a static budget over the last five years, also negatively impacted collection development. This state of affairs is familiar to most academic institutions. The UNLV libraries have been more fortunate than most, as they were not forced to make significant journal cancellations until 1999. Further complicating access to resources, UNLV is geographically isolated from other academic universities. Its sister institution, the University of Nevada, Reno, is 450 miles away and the nearest academic libraries are at least 250 miles away in the states of California, Arizona, and Utah. Nevertheless, some faculty members regularly visit the libraries at those institutions to conduct research.

The UNLV libraries provide access to more than 80 online indexes in addition to the standard print ones. While online indexes have proven to be popular resources, they frequently give rise to user frustration when the list of citations includes many journals not available locally. The availability of full-text indexes has largely satisfied undergraduate needs at UNLV with a few exceptions (e.g., health sciences) but has meant little to research faculty.

One of the prime motivations behind the decision to implement unmediated document delivery service in late 1998 was an anticipated journal cancellation project. The flat budget forced the libraries to drastically reduce the purchase of monographs in order to support the journal collection. To avoid a further decrease in monograph acquisitions, a major serials review and cancellation process was initiated. In addition, the retirement of several long-term interlibrary loan employees, and an accompanying reorganization, had led to a serious backlog in interlibrary loan requests. These factors indicated that the time was right to initiate this new service. Staff planned to have it operational by the beginning of the January 1999 spring semester.

A review of library literature revealed that the issues of expanding collections, offering enhanced service, and reducing interlibrary loan workload and staff triggered the initiation of unmediated document delivery projects at a number of other institutions. The main motivation for trying unmediated document delivery, the institution, document supplier(s), and author(s) are displayed in table 1 to give an overview of the more recent studies.

Table 1. Unmediated Document Delivery Studies

\begin{tabular}{llll}
\hline Motivation & Institution & Document Supplier & Study \\
Expand access to non-owned titles & Aalborg Univ. (Denmark) & Uncover & Arkin (1998) \\
Expand access, reduce ILL & Texas A\&M & British Library, ISI, EbscoDoc, UMI & Crowley (1999) \\
Expand collections, identify journal needs & Louisiana State Univ. & UnCover & Kleiner and Hamaker (1997) \\
Enhance collections & Utah State Univ. & EbscoDoc & Kochan and Elsweiler (1998) \\
Reduce ILL & Texas A\&M & ProQuest Direct & Thornton and Jackson (1997) \\
Expand access & Arizona State Univ. & OCLC's FirstSearch, RLG's Eureka/CitaDel, & Walters (1996) \\
& & UnCover & \\
\hline
\end{tabular}


Expanding or enhancing collections is the most prominent motivation for implementing unmediated service. Implicit within offering the service is the attempt to meet a growing demand for materials beyond local capabilities in a convenient way that promises a quicker delivery time than interlibrary loan. As stated by Kochan and Elsweiler (1998), the Internet and electronic information technologies present new opportunities for satisfying information needs. At Louisiana State University, unmediated document delivery was one prong of an aggressive plan to manage serials expenditures (Kleiner and Hamaker 1997). Two of the studies offered more than one document supplier. Appropriate coverage, billing centralized at the library, and delivery options other than faxing were reasons cited for offering more than one supplier (Walters 1996). Crowley (1999) noted that data on usage patterns for different delivery methods and suppliers was gathered.

\section{Selection of Users}

Due to requests for new journals, UNLV faculty members were targeted as those who would benefit most from unmediated document delivery. In the face of impending serials cancellations, starting new subscriptions was not possible. Concurrently, the growth of new programs and the hiring of new faculty emphasized the need for access to more journals, especially in emerging areas of research. Providing wider access through unmediated document delivery appeared the most likely solution to the need for more resources. However, from the beginning, some faculty members were adamant that unmediated document delivery was no substitute for subscriptions. Taking this into account when talking with faculty members, librarians emphasized that document delivery was not perceived to be better than local availability, but was designed to provide access to material that for one reason or another could not be obtained locally.

\section{Choice of Document Supplier}

In 1988, the Colorado Alliance of Research Libraries (CARL) began offering a current awareness/document delivery service to subscribers. For a modest fee, CARL e-mailed the tables of contents of selected journals to subscribers who could also request documents for facsimile delivery by responding to the e-mailed message. It was also possible to search the database by author or keyword, and to browse by journal contents. This service, now known as UnCover, has grown to include 18,000 journals. Although the UNLV Libraries facilitated access to the UnCover database since its inception in 1988, use of the document delivery service was limited to the interlibrary loan department. Access was provided in order to permit students and faculty to search the database in much the same way that access is provided to other electronic indexes, that is, to provide bibliographic references and not necessarily to enable document delivery. UnCover's broad subject coverage, along with local familiarity with this service, were deciding factors in the selection of UnCover as the document supplier for UNLV.

Sellers and Beam (1995) contended that an ideal document delivery service would allow:

- user-initiated electronic ordering from within a bibliographic database;

- ease of use to minimize the need for assistance;

- no use of library staff for processing, i.e., unmediated direct delivery to the user;

- linkage to library holdings to enable an automatic block for articles available locally;

- reasonable charges comparable to interlibrary loan;

- automated reports;

- a collection of journals satisfying most local needs; and

- multiple delivery options.

UnCover more or less meets these eight requirements, although it is weak in the area of multiple delivery options. Its merger with www.ingenta.com may strengthen this substantially, but has not yet impacted the service at UNLV. The UNLV libraries did not seriously consider other vendors for the initial implementation of unmediated document delivery in order to avoid the introduction of more interfaces and the logistics of setting up multiple accounts with different vendors. The $\$ 10,000$ cost to purchase the ability to block ordering UNLV-owned articles seemed prohibitive. While the ability to receive articles via Ariel or regular mail would have been welcome, it was not considered critical to the success of the service.

\section{Training}

Before extending the option of unmediated document delivery to all UNLV faculty, representatives from the library departments of Instruction, Interlibrary Loan, and Collection Development met to determine content for instruction and to schedule training sessions. Results of a pilot study had indicated that failure to provide adequate training resulted in minimal use of the service. Staff concluded that effective user training was critical to the success of the project. The UNLV Libraries publicized the availability of the service in several ways, sending flyers to every faculty member, e-mailing messages via the campus information electronic discussion list, and placing announcements in sev- 
eral campus publications. The service was open to all faculty members and there was no attempt to focus only on new faculty, active researchers, or frequent users of interlibrary loan services.

A series of one-hour classes were scheduled in the library's electronic classroom. Class attendance or individual training was required before a user could obtain an account password for UnCover, which was similar to the project Crowley (1999) described at Texas A\&M. During January, February, and March of 1999, eight classes were held to instruct faculty on how to set up a profile, how to search UnCover, and how to order articles. Prior to the sessions, a librarian set up the user's initial profile. The classes were hands-on learning experiences in which attendees worked with their individual profiles and tailored them to their needs. The library established two policies: (1) only articles from journals not owned by UNLV could be ordered and (2) the library would subsidize the cost of articles costing $\$ 35$ or less. Instructors heavily emphasized the two rules as part of the instruction. If faculty members wanted to order articles that cost more than $\$ 35$, they were told to request them through Interlibrary Loan. It was emphasized that if time was not an issue, documents should continue to be ordered through interlibrary loan. Despite concerns about cost, no limit was placed on the number of articles that could be ordered. Enthusiasm for the service was high among those at the training sessions.

Kleiner and Hamaker (1997) organized training sessions for subject selectors to familiarize them with the larger serials assessment project and the UnCover service. The UNLV project organizers initially anticipated that the subject selectors would serve as liaisons for UnCover services to their departments. However, eventually two librarians, both science subject specialists, became the sole trainers/coordinators. One librarian trains users and maintains the profile database; the other trains users and serves as the coordinator with UnCover. The coordinator also receives and reviews the monthly reports from UnCover, and notifies users when they have violated the library document ordering policies.

\section{Monitoring}

The UNLV Provost had allocated $\$ 25,000$ to the library for document delivery services; of this, $\$ 10,000$ was placed in a deposit account with UnCover. A master rollover account was set up with 48 subaccounts, one for each of 47 departments and a general account for other faculty such as researchers or administrators. While there were separate accounts for each academic department, there was no budget per department. Separate accounts allowed the tracking of expenditures by department. In addition, they provided the library with more control over passwords. If one department's password was compromised, it could be changed without affecting any of the other departments. In implementing the service at UNLV, it was considered imperative to keep detailed records of usage for both financial and collection development reasons. Access, Microsoft's database application, was chosen to create a database to store departmental account numbers, deposit account passwords, faculty profile numbers, and use statistics. Access was used because it could provide needed functions and was available at each librarian's desktop. The database was created on a shared drive so that the two librarians coordinating the project could both keep it updated, providing a centralized resource where current information could easily be obtained. A record of departmental account numbers and passwords was necessary to efficiently track usage. While UnCover sends a monthly statement of orders broken down by departmental account, these statements come one month after the end of the month being reported; that is, January's report comes at the end of February, and so forth. If faculty members ordered articles from journals subscribed to by the library, the librarians wanted to alert them to the error before two months had passed. By taking advantage of UnCover's online report feature, a listing of the orders placed on an account for a rolling 60 days could be downloaded and reviewed weeks before the print report was received.

A macro was written that would format the order data retrieved from the online UnCover reports so the information could be easily imported into Access. Downloading the information and putting it in the database took about one hour per month. Print reports were used to verify the downloaded data. The use of this database made it possible to analyze aspects of use such as the quantity of articles ordered by department, amount spent per department, the request rate of a specific journal, and the number of requests for articles from journals held by the library.

A record of the profile numbers was kept in case faculty members lost or forgot their numbers. Faculty members chose their own profile passwords and the library did not keep a record of them, according a small amount of privacy to the profile. A user who misplaced or forgot a profile password was able to call UnCover's toll-free telephone number and obtain it by providing the profile number. As a further measure of confidentiality, although the name of the person ordering each article was listed on the monthly report, the library did not have access to the keyword searches or the names of journals from which tables of contents were being e-mailed. Keeping track of e-mail addresses made it easy to contact faculty if they left a question or needed to be notified of problems with their orders. Keeping this data also allowed us to quickly view how well each department had responded to the service. 


\section{Findings Pilot Studies}

One pattern that became apparent in analyzing unmediated document delivery projects was the preference for starting the service as an experiment or pilot study. Arkin (1998) termed the service experimental. Crowley (1999) conducted a study that lasted for two semesters. At Louisiana State University, a pilot in the chemistry department expanded to a pilot that included all sciences (Kleiner and Hamaker 1997). Kochan and Elsweiler (1998) tested the service on ten active researchers from the two departments that were most insistent on obtaining new journal subscriptions. Thornton and Jackson (1997) conducted a pilot study with a technical writing class for one semester. At Arizona State University, a yearlong pilot project was conducted (Walters 1996). Rather than opening the option of unmediated document delivery to a wide group of users, libraries implemented trials by testing the service on a target group. For the most part, the goals of these studies were to control expenditures and to discover if use patterns would emerge. Testing the service on a small group would serve to indicate if it should be continued or expanded to larger groups.

Recurring discussions had taken place concerning whether or not to implement an unmediated document delivery service for faculty members at UNLV. The main impediment to offering the service was a difference in opinion over the extent to which the library would subsidize the cost. Some librarians were of the opinion that a minimal fee of $\$ 1$ or $\$ 2$ per article should be charged, arguing that if the service were free to faculty, faculty members would place frivolous orders and not consider the cost. Without knowing how the service would be used, the library administrations were conservative in selecting users in order to minimize costs. They did not wish to start a project that would have to end early because of cost overruns. Despite this perceived risk, the decision was made to begin the pilot project with the library subsidizing all expenses. Two departments were selected and their faculty members were allowed to order journal articles from the UnCover service.

The goal of the project was to explore the financial impact on the library's budget of faculty ordering articles directly from a document provider versus using the standard interlibrary loan process. By testing use in two departments the potential for abuse could be gauged and the final decision about totally or partially subsidizing document delivery could be made at a later date. Furthermore, patterns of ordering might become apparent that would give an indication of whether or not it would be feasible to expand the service to faculty in all departments.

The project began in late fall 1997. The two departments selected to participate were Physics and Civil and Environmental Engineering. The Physics department had just undergone an external review that stated that document delivery was a valid alternative to subscribing to more journals. A similar review of the Civil and Environmental Engineering program suggested the need for a branch library that would focus on purchasing relevant materials. These reviews made it obvious that these two departments would be prime candidates for the trial. In the case of Civil and Environmental Engineering, unmediated document delivery would be a way to get materials without the overhead of another library. Additionally, both departments were in technical areas where journals are expensive and a preferred source of information.

A memo describing the UnCover service was sent to each faculty member in the two departments. The message explained that the library would subsidize the purchase of articles costing $\$ 35$ or less from journals not subscribed to by the library. Individual appointments were scheduled with those who responded; those who had not responded were contacted by e-mail and telephone. The appointments were held in the faculty member's office. At that time an UnCover Reveal profile was created. A profile contains information about the user, such as telephone and fax numbers as well as the preferences for tables of contents and search strategies for weekly e-mail alerts. The participant was given instructions on how to order articles and set up e-mail alerts. The librarian emphasized both the price limit of $\$ 35$ per article and the need to check local holdings before ordering. A handout with instructions for ordering and the policies was left with each faculty member for future reference.

UNLV's pilot study lasted one year, ending in the fall of 1998. During that time about one-third of the Physics faculty set up accounts; one-third said they were not interested; and one-third never responded. Every member of Civil and Environmental Engineering but one started accounts. Faculty members ordered a minimal quantity of articles during the pilot project, amounting to less than $\$ 200$. At least for the two departments that participated, the fear of frivolous ordering had proved groundless. Review of the trial indicated that there was no increase over normal document delivery costs during that time. When the decision was made to expand unmediated document delivery to all UNLV faculty, no modifications to the policies used during the trial were made.

\section{Success of the Service in Meeting Stated Needs}

Unmediated document delivery was tried for the following reasons: (1) to supplement collections; (2) to provide service to users; (3) to cut interlibrary loan workload or costs. The impact of using the service will be examined to determine whether the service was successful in answering the needs in these areas. 


\section{Supplement to Collections}

At UNLV the first year of service was 1999, before 717 journal cancellations for 2000 took effect. By the end of June 2000, after 18 months of service, UNLV faculty obtained 719 articles at a cost of $\$ 17,215.19$, averaging $\$ 23.94$ per article. Articles from 425 different journal titles were ordered. The library did not own 309 or $72 \%$ of the titles; the remaining 116 were in the collection. Unmediated document delivery served to supplement the collection without subscription and processing costs. The journals ordered ten or more times are listed in table 2.

As illustrated by table 2 , the subscription price is greater than the amount paid for individual articles in most cases. Faculty members have expressed interest in subscribing to Water Science and Technology. However, purchasing articles over an 18-month period cost less than one-seventh of a oneyear subscription. For example, the Journal of Clinical Geropsychology appears to be less expensive to subscribe; at first glance it seems that subscribing for $\$ 223$ would be more cost effective than paying to order 12 articles for $\$ 312$. Upon further investigation, it turns out that the articles were ordered from issues ranging over a period equivalent to three subscription years, i.e., orders were for articles from 1997, 1998, and 1999. Subscribing for three years would cost at least $\$ 670$, more than twice the amount paid by purchasing individual articles. Kleiner and Hamaker (1997) concluded that it was more cost-effective to purchase by the article rather than to subscribe to high-cost journals, even for titles ordered ten or more times.

Though the collection was supplemented by unmediated document delivery, many orders duplicated library holdings. Of the articles ordered, $23 \%$ were from journals owned by the library. Orders in violation of the not-owned policy totaled $\$ 3,365$, $19 \%$ of the cost of all articles delivered. In most cases, the issue requested had been checked in at the time of the order and receipt would have been reflected in the catalog; in a handful of cases the article was ordered before the issue had arrived. The subscription to Physical Therapy includes both print and online access. A quick check of the catalog would have allowed the requestor to print articles immediately rather than wait for faxes. The library does not have a print subscription for Aids and Behavior but electronic-only access is available through a package deal with Kluwer. Availability of electronic formats provides the convenience users seek but they have to be willing to search the catalog to find and use online journals.
Users were notified when they ordered articles held by the libraries and when electronic access was available. One responded that the issue was not on the shelf when she looked. Most said they would be more careful. Table 3 shows the distribution by department of the number of owned articles ordered and their cost. The Psychology and Biological Sciences departments ordered the most articles and the most duplicates. Even library faculty requested owned articles, making it difficult to expect that faculty in other departments would not do the same.

The ordering pattern suggested that the convenience of submitting orders from search results facilitated requesting articles owned by the libraries. Individuals tended to order a group of articles then not order again for a few months, if at all. Up to five to ten articles would be selected and then ordered all at one time. Once the ordering momentum started, the users requested all the articles they selected rather than checking the library's holdings. The highest number of articles ordered in one session was 34, five of which were duplicated in the collection.

Table 3. UNLV Orders Duplicating Collection by Department January 1999-June 2000

\begin{tabular}{lrr}
\hline Department & Duplicate Articles & Cost \\
Biology & 54 & $\$ 1,117.05$ \\
Psychology & 46 & 991.00 \\
Mechanical Engineering & 19 & 463.10 \\
Physical therapy & 14 & 223.30 \\
Social work & 12 & 202.50 \\
Accounting & 9 & 157.50 \\
Marketing & 5 & 86.45 \\
Nursing & 2 & 42.00 \\
Library & 2 & 26.25 \\
English & 2 & 24.25 \\
Hotel Mgt. & 1 & 13.25 \\
Chemistry & 1 & 18.50 \\
Total & 167 & $\$ 3,365.15$ \\
\hline
\end{tabular}


As stated earlier, supplementing the existing collection was a key reason for trying unmediated document delivery in most studies. Expanded access to nonowned titles was achieved either by browsing tables of contents or ordering individual articles from titles not held. Walters (1996) observed that the requests from a given journal frequently came from one or two regular users. Thus there was not enough combined interest in the particular journal to make purchase a priority. Studies that had not blocked ordering on holdings reported that, from $10 \%$ to $80 \%$ percent of the articles ordered existed in their collections, which meant that to varying extents collections were being duplicated rather than supplemented.

\section{Service to Users}

At UNLV, 133 of approximately 750 faculty members from 41 departments signed up for the service. Of that number, 56 , representing 21 departments, ordered a total of 840 articles in the first 18 months. Biology ordered the most at 252 articles, $30 \%$ of the total number ordered for that period. Psychology was second with 226 orders or $26.9 \%$ of the total ordered. Table 4 illustrates the number of orders by department and their cost. The current awareness service has proven at least as popular among UNLV faculty as document delivery.

Fill rate is an important measure of service. UNLV faculty ordered 840 articles, of which 83 were cancelled, for a fill rate of $85 \%$. In about 30 cases, UnCover was unable to supply the request, other reasons for cancellation included inability to connect to the fax number supplied by the user, duplication of an existing order or cancellation by the requestor. When an article could not be supplied, notification was within the expected time of receipt. There were few complaints of unreliable delivery from the faculty. Crowley (1999), whose study used multiple document suppliers, also reported satisfaction with the fill rate at her institution.

The speed of delivery was another measure of service. UNLV experienced an average turnaround time of 1.07 days from the time of ordering to the time of delivery, almost exactly the 24 hours advertised by UnCover. A large percentage of the articles, $49.6 \%$ or 357 , were delivered on the same day. The longest delivery time was nine days for one article, a rate faster than the average interlibrary loan transaction.

Several factors entered into assessing the quality of the delivery service. UnCover is somewhat limited in its search capabilities and has no abstracts. Furthermore, since UnCover is basically a journal table of contents database, it does not provide citations to conferences or proceedings. These limitations have not been a major concern to most users, who are more concerned that the database only goes back to 1988 and lacks abstracts. The unsophisticated search

\begin{tabular}{lrr}
\hline Table 4. UNLV Orders by Department, January & 1999-June 2000 \\
\hline Department & Articles Delivered & Cost \\
Biology & 252 & $\$ 6,015.57$ \\
Psychology & 226 & $5,730.50$ \\
Mechanical Engineering & 62 & $1,566.60$ \\
Social Work & 48 & $1,100.25$ \\
Accounting & 48 & 922.50 \\
Library & 29 & 800.97 \\
Marketing & 17 & 287.45 \\
Nursing & 9 & 186.00 \\
English & 5 & 65.25 \\
Math & 5 & 144.00 \\
History & 3 & 57.35 \\
Electrical Engineering & 2 & 60.00 \\
Curriculum & 2 & 41.25 \\
Civil Engineering & 2 & 40.50 \\
Chemistry & 2 & 56.50 \\
Anthropology & 2 & 30.00 \\
Other* & 5 & 110.50 \\
Total & 719 & $\$ 17,215.19$ \\
\hline
\end{tabular}

* The following departments ordered one article each: Criminal Justice, Hotel Management, Kinesiology, Philosophy, and Sociology.

capabilities seem to be of more concern to librarians than other faculty. Members of the UNLV faculty were pleased to learn of the Reveal e-mail alerting service. Indeed, some faculty members set up profiles just to get the e-mail alerts while preferring to get photocopied articles from interlibrary loan rather than faxed copies from UnCover.

The major complaint about the service was the quality of reproduction in the faxes that were received. At least one professor stated that the faxes were not usable and he would make no more orders from Uncover. These complaints were most often heard from the scientific disciplines, in part due to the preponderance of formulas, charts, and photographs in their articles, which do not fax well. This problem is not unique to UnCover; Utah State University had the same complaint in their experiment with EBSCOdoc (Kochan and Elsweiler 1998). While few people at UNLV tried out UnCover's desktop delivery option allowing scanned images to be printed, those that did complained about its effectiveness. A special viewer (CarlView) had to be downloaded and in several cases the person's session timed out during the download resulting in the loss of the document. Other limitations in service included lack of coverage comprehensive enough for in-depth research.

\section{Effect of Unmediated Document Delivery on Interlibrary Loan Staff or Workload}

A list of faculty who ordered articles from interlibrary loan during 1999 was compared to the names of those using unmediated document delivery for the same time period. Orders for interlibrary loans are submitted electronically and 
do not require that a person visit the library. Half of the 36 who used unmediated document delivery made no requests from interlibrary loan, preferring to order the documents themselves. Five faculty members used both but ordered more from UnCover than interlibrary loan. It could not be confirmed that they ordered through interlibrary loan because the articles were not available from UnCover. Thirteen of the participants used both but ordered more from interlibrary loan than the unmediated service. Interlibrary loan did not experience a decrease in article orders after unmediated document delivery was implemented. Indeed, the number of interlibrary loan requests has grown over the last two years. For fiscal year 1998-99, faculty requested 3,154 articles from interlibrary loan. The 1999-2000 fiscal year saw an increase to 3,731. During 1999-2000, faculty ordered another 629 articles via UnCover. Demand for interlibrary loans has steadily increased during the time unmediated document delivery has been an option. Arkin (1998) also reported constant increases in interlibrary loan concurrent with the availability of unmediated service, explaining it as expanding into a new service market rather than transferring an activity from staff to users. Two studies targeted active interlibrary loan users for their pilots; one selected a class of 23 students and the other used ten active researchers, but the populations were too small to have an impact on overall interlibrary loan activity (Thornton and Jackson 1997; Kochan and Elsweiler 1998).

\section{Appropriateness of Selected Users in Meeting the Stated Need}

UNLV opened the service to faculty in all departments. Though reduction in interlibrary loan costs and workload were motivating factors in using unmediated document delivery, no attempt was made to target those making numerous journal requests from interlibrary loan or those conducting high levels of research. Rather than offering the service directly to heavy interlibrary loan users, it was assumed that they would switch to unmediated document delivery along with the rest of faculty. In practice, interlibrary loan users did not switch. Some faculty used both, but unmediated document delivery did not substitute for interlibrary loan. Many faculty stated a preference for photocopies rather than faxed material. The Web form for interlibrary loan requests is a selection on the main menu of the catalog that can be filled out between searches for holdings. To do a search in one database, checking the catalog for holdings and then switching to UnCover to order adds a step that interlibrary loan avoids. If UnCover is unable to supply the desired article, an interlibrary loan request has to be made anyway. So far, unmediated document delivery has not converted interlibrary loan users but has attracted a different segment of the university community.
All of the articles ordered appeared to pertain to academic activity and were not ordered for personal interest. Biology, one of the departments whose faculty were substantially involved in active research, requested the most articles. Art, Dance, Film, Environmental Studies, Health Education, Health Physics, Theater, and Educational Leadership had no participants. That the fine arts departments of Art and Dance do not use the service is not surprising since the scholarly activities of the UNLV fine arts faculty are generally performance oriented. The library had the largest number of registered users, 18. Librarians ordered 29 articles and appeared to use the service more for current awareness.

\section{Choice of Document Supplier}

Overall the UnCover service was well-received and appreciated by UNLV faculty. In addition, the library is implementing additional document delivery services that will be able to provide conference papers and journal articles in high-resolution formats. The two services that have been selected to supplement UnCover are the Canada Institute for Scientific and Technical Information (CISTI) and Ei Electronic Text Services.

CISTI supplies scientific, technical, and medical documents to North America. Its 24-hour database contains citations to journal articles, conference proceedings, and technical reports. The documents can be delivered electronically, requiring Ariel software on the receiving end to read the file and produce high-resolution printouts. A pilot project using CISTI is being coordinated with the Biology department. The library has purchased a copy of Ariel software (receive only) that has been installed on a computer in the Biology department. If the trial is successful, the service will be extended to other departments within the Colleges of Science and Engineering.

The other service being implemented, Ei Electronic Text Services, is used from within COMPENDEX, an engineering bibliographic database. As is the case with CISTI, journal articles and conference papers can be ordered directly from citations in the database. The requestor has the option of receiving the document by e-mail in .pdf file format. This format offers the ability to print documents at a high resolution so that graphics are clearly legible. The documents can be viewed with readily available Adobe Acrobat software.

The library has set up a deposit account and supplied Ei Electronic Text Services with the ISSNs of library journal holdings, thus permitting citations in COMPENDEX to link to UNLV's subscribed titles. If the citation a searcher retrieves is for an article or paper that the library owns, a message to that effect is displayed. The faculty members that have tried it are pleased with the quality of .pdf images. 


\section{Effectiveness of User Training}

Analysis of the orders placed indicated that UNLV faculty members needed reinforcement in learning to check the library catalog for subscriptions. In addition, they would benefit from being able to determine quickly which full-text journals are available. They could print articles from those resources rather than ordering duplicates from UnCover. Faculty members were encouraged to order their own articles only if they were in a hurry to get them. This point appears to have been lost since many do seem to order on impulse. As mentioned earlier, the pattern of ordering several articles at the same time seems to contribute to these impulse orders. Even with instruction, ordering of owned items was still frequent. It is quite possible that it would have been yet more frequent without instruction. Crowley's (1999) user survey found that users did not want to take the additional step of consulting the catalog but wanted holdings linked in the index they searched.

\section{Necessity of Monitoring Use}

At UNLV, reports were checked to identify orders from journals owned by the library. E-mail was sent to the person who had requested those items. The e-mail message contained the title, call number, and cost of the orders, accompanied by instructions on how to check holdings in the library catalog. Patrons were informed that if duplicate orders continued, their account could be terminated though none have been so far. If the order had been placed within a few days of receipt of an issue, an e-mail was not sent. As mentioned earlier, although orders for owned articles were frequent, paying for the service to block orders based on holdings was many times more expensive. However, it may be more cost effective to pay the fee than to monitor use so closely. Sending e-mail warnings is time consuming, as each owned article has to be checked against that issue's receipt date, and the titles, call numbers, and cost of articles sent to the users who may or may not remember to check the cata$\log$ when they order again in a few months. Crowley (1999) asked users to log orders but they failed to do so and the time-consuming task of tracking invoices fell to the library staff. It cannot be assumed that faculty will take the same care in making orders as library staff. Unless tracking use can be automated to a large extent, having the library staff track orders can be time consuming and should be weighed against the time needed for interlibrary loan to process orders.

\section{Continuation of Unmediated Document Delivery}

After starting unmediated document delivery as a pilot project or temporary service, several institutions continued to allow users to order articles for themselves on a permanent basis. In some cases modifications to make better use of local collections were made. At Aalborg University, it was determined that blocking orders of holdings was considered to be financially advantageous to continuing the service as long as a free copy ordering service could be instituted to deliver articles held in the collection (Arkin 1998). Walters (1996) reported continued service with modifications including links to holdings in UnCover with a block on ordering items in the collection. A service called Library Express delivered owned articles directly to faculty members. At the time it was yet to be determined if Library Express was more cost effective than unmediated document delivery. Louisiana State University implemented links to holdings in UnCover and blocked orders of owned items (Kleiner and Hamaker 1997). They found that purchasing on a per-article basis cost less than one-fifth the amount saved by journal cancellations. At Utah State University, Kochan and Elsweiler (1998) stated that faculty expressed an interest in continuing the service after the pilot. Modifications were not suggested for the service itself but for who would pay. Rather than having the library fully subsidize the service, the library, vice-president for research, and departments that wanted to participate would each contribute one-third of the cost. Unmediated document delivery is going into a third year at UNLV. At this time, the cost to link holdings and block orders on UnCover is still many times more expensive than paying for duplicate orders.

\section{Considerations in Using Unmediated Document Delivery}

As a result of experience in using unmediated document delivery, it was hoped to develop some criteria that would help determine when the service could be employed most effectively. Uncertainty about offering the service could be tempered by having specific criteria to aid in decision-making. Collections of any size benefit from expanded access to materials much as with interlibrary loan. Paying per article is less expensive than subscribing to costly titles or to titles with few users. Some questions to consider before offering unmediated document delivery include:

- How will the ordering of duplicate articles be handled?

- Is it cost effective to block orders on holdings?

- How will use be monitored?

- Who will monitor use?

- Does the service provide materials that meet the needs of the users?

- Can orders be made directly from search results?

- Are documents delivered directly to user desktops or offices? 
- How will users be instructed in using the service?

- How will realistic expectations of turnaround time and quality be imparted to the user?

- Is the cost to train users, monitor use, and block orders from holdings less than interlibrary loan?

- Are heavy interlibrary loan users being targeted to use the service if the intent is to reduce interlibrary staff or workload?

\section{Conclusion}

Unmediated document delivery has the potential to affect library collections, services, and staffing. Collections are expanded by facilitating access to nonsubscribed journals. However, frequent ordering of articles contained in the onsite collection is counter to this purpose. Measures may have to be taken to prevent spending on duplicates. This leads to paying to link holdings and blocking duplicate orders or to having library staff check holdings before orders are placed. The cost of paying to link holdings has to be weighed against subscription costs, the amount of money lost through duplication, and the cost of processing by library staff. Having library staff check orders defeats the purpose of eliminating the "middleman" to expedite ordering and delivery. Unmediated document delivery added a new service for library users. Users appreciated the service often preferring it to interlibrary loan. Since for the most part the users were not regular interlibrary loan customers, they did not decrease the workload or costs associated with interlibrary loan. Unmediated document delivery users did not effec- tively replace library staff labor. Unmediated document delivery offers libraries another service option but tradeoffs may mean that staff time or money saved in one area is costing time or money in another. Awareness and consideration of the tradeoffs can be applied to determine whether or not unmediated document delivery serves the needs both of users and the library.

\section{Works Cited}

Arkin, Elizabeth. 1998. User initiated interlibrary loan. Interlending and Document Supply 26 (3): 119-22.

Crowley, Gwyneth H. 1999. Unmediated document delivery: A project using FirstSearch and EBSCOdoc. Interlending and Document Supply 27 (3): 122-27.

Kleiner, Jane P., and Charles A. Hamaker. 1997. Libraries 2000: Transforming libraries using document delivery, needs assessment, and networked resources. College and Research Libraries 58 (July): 355-74.

Kochan, Carol A., and John A. Elsweiler. 1998. Testing the feasibility of unmediated document delivery services with EBSCOdoc: The Utah State University experience. Journal of Interlibrary Loan, Document Delivery and Information 9 (1): $67-77$.

Sellers, Minna, and Joan Beam. 1995. Subsidizing unmediated document delivery: Current models and a case study. Journal of Academic Librarianship 21: 459-66.

Thornton, Joyce K., and Kathy M. Jackson. 1997. Using ProQuest Direct for do-it-yourself document delivery: A case study. Online 57 (March/Apr.): 57-63.

Walters, Sheila A. 1996. End-user document delivery service: To mediate or not to mediate. Colorado Libraries 22 (fall): 11-13. 